\title{
Milia en Plaque of the Earlobe
}

\section{Anca CHIRIAC ${ }^{a}, b, c$, Uwe WOLLINA ${ }^{d}$, Cristian PODOLEANU ${ }^{\mathrm{e}}$, Simona STOLNICU ${ }^{f}$}

a'Department Dermatology, Apollonia University, lasi, Romania

bDepartment Dermatology, Nicolina Medical Center, lasi, Romania

'Department of Macromolecular Chemistry, P. Poni Institute, lasi, Romania

'Department of Dermatology, Venereology and Allergology,

Academic Teaching Hospital Dresden-Friedrichstadt, Dresden, Germany

eDepartment of Cardiology, University of Medicine, Pharmacy,

Sciences and Technology of Targu Mures, Romania

'Department of Pathology, University of Medicine, Pharmacy,

Sciences and Technology of Targu Mures, Romania

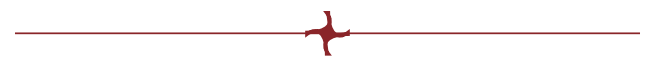

ABSTRACT
Introduction: Milia en plaque is an uncommon benign dermatosis.

Case presentation: We present a case of a 43-year-old Caucasian man with a five-month history of asymptomatic symmetric lesions on the earlobes that has been previously treated by self-medication with potent topical steroids, emollients, cosmetic procedures, herbal medication and punch-procedure. Based on clinical examination, a diagnosis of milia on earlobes was established and treated with topical steroids.

Conclusions: Milia en plaque of the earlobes has yet not been reported. Treatment is not different from other localizations.

Keywords: milia en plaque, topical retinoids, earlobe.

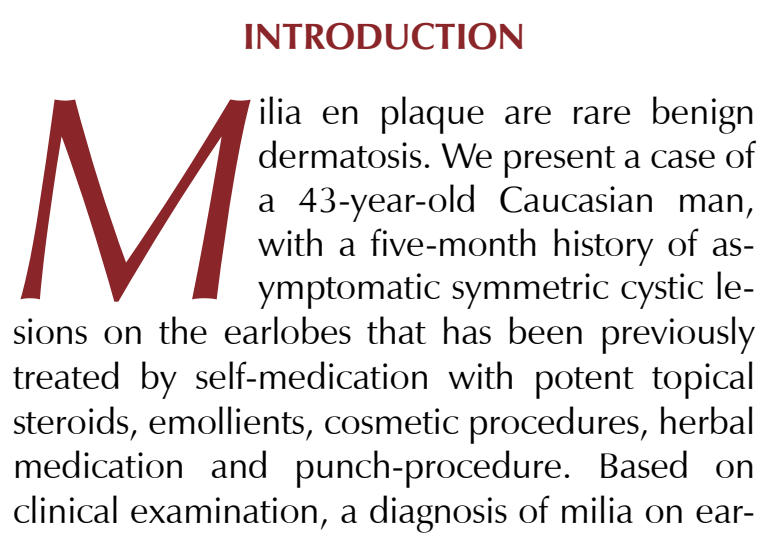

lobes was presumed, with complete healing after topical retinoids.

\section{CASE REPORT}

43-year-old Caucasian man presented with a five-month history of asymptomatic symmetric lesions on the earlobes that has been previously treated by self-medication with potent topical steroids, emollients, cosmetic procedures, herbal medication and punch-procedure. The patient was a healthy person, with negative fami-

Address for correspondence:

Simona Stolnicu (ORCID ID: 0000-0002-4459-7019)

Department of Pathology, University of Medicine, Pharmacy, Science and Technology of Targu Mures, 38 Gheorghe Marinescu Street, Targu Mures 540139, Romania

Tel.: +40265215551, Fax: +40744765716, email: stolnicu@gmx.net

Article received on the $22^{\text {nd }}$ of November and accepted for publication on the $8^{\text {th }}$ of December 2021 


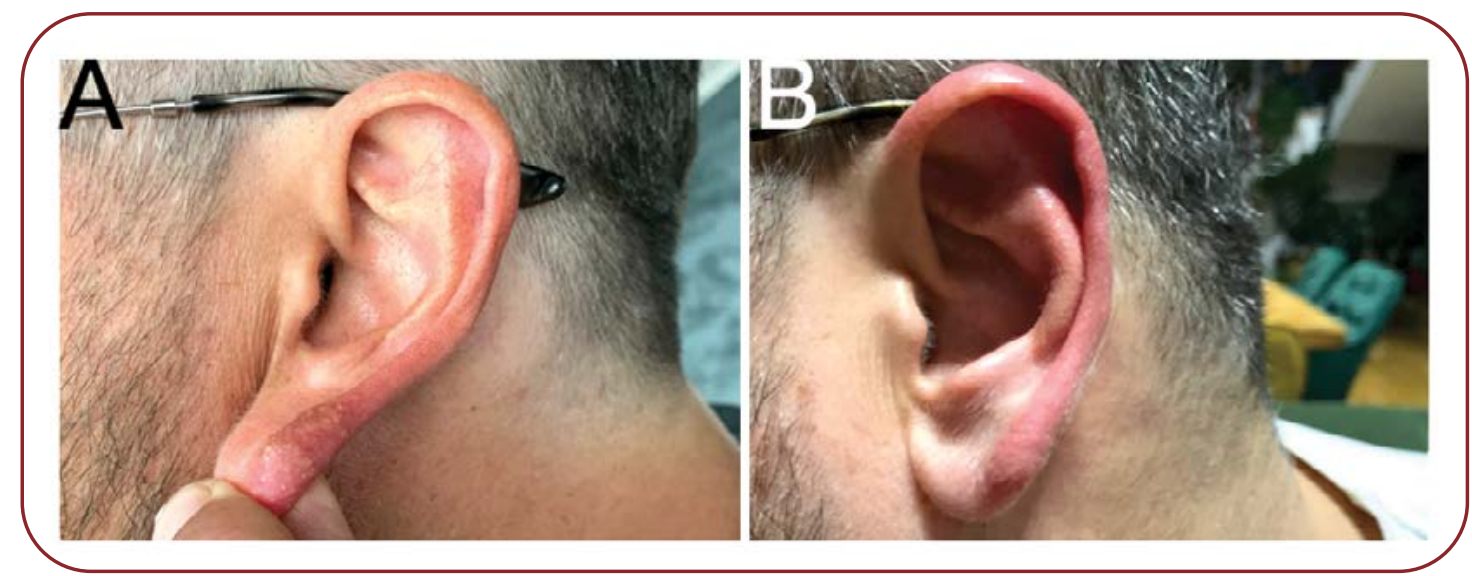

FIG URE 1. Milia en plaques on earlobes before treatment (A) and after treatment (B)

ly history for skin disorders and very anxious due to newly onset skin lesions on the earlobes. On clinical examination, numerous tiny, whitish, 1-2 mm diameter, spread cysts were noticed on the earlobes, which were completely asymptomatic but quite visible from distance. No other skin lesions were observed on any other part of the body, no mucous lesions. Skin biopsy was denied by the patient due to fear of scars. A clinical diagnosis of milia was presumed and two-month treatment with daily application of topical tretinoin was recommended. The patient was satisfied with the results when he was reexamined at two months of treatment, with almost complete disappearance of milia. Close follow-up was done and the six-month control revealed no lesions (Figure 1 ).

\section{DISCUSSION}

M ilia are encountered as tiny epidermal cysts probably of vellus hair follicles with a whitish color. Primary milia can be separated from secondary milia which develop on an underlying pathology like porphyria cutanea tarda, burn scars or certain genodermatoses (1).

Milia en plaque (MEP) is a rare cystic hamartoma with trichoepithelial features, which has been first described by Balzer in 1903 (2). The term MEP was coined by Hubler in1978 (3).

Multiple milia are grouped together on an erythematous plaque. Dermoscopy reveals numerous white or white-yellow cystic structures of variable size, scattered brown dots and telangiectatic blood vessels. Histologically, multiple cystic structures can be found at different dermal levels, which are lined by a stratified squamous epithelium. Cysts are filled with keratinous material and may be surrounded by a mononuclear inflammatory infiltrate $(4,5)$.

Milia en plaque can occur at any age (6). The mean age in a review on 53 cases was 38.7 years. Females are affected double as much as males. It is most commonly localized in the head and neck area (5). The majority of MEP is unilateral, but bilateral occurrence has been reported occasionally $(7,8)$.

The outer ear and auditory canal were affected in several cases (9-12), but involvement of the earlobe has yet not been reported to the best of our knowledge.

Treatment is warranted due to esthetic reasons. There is no standard therapy for MEP, but topical tretinoin (13) oral etretinate (14), photodynamic therapy (PDT) with methyl aminolevulinate hydrochloride (12), erbium-YAG-laser (15), fractional C02 laser (16), radiofrequency (8), electrodesiccation (17), and microwave thermotherapy can be used (18).

\section{CONCLUSIONS}

The present case has the following particularities: male patient with abrupt onset of milia localized symmetrically on earlobes, treated with topical retinoids with perfect results.

Ethic Statement: The paper is exempt from ethical committee approval according to the local rules. Written informed consent was obtained from the patient for publication of this case report and any accompanying images.

Conflicts of interests: none declared.

Financial support: none declared. Equal contribution of all authors 


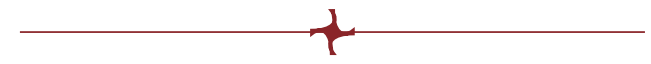

\section{R Eferences}

1. Berk DR, Bayliss SJ. Milia: a review and classification. J Am Acad Dermatol 2008;59:1050-1063.

2. Balzer FFC. Milium confluent retroauriculaires bilateral. Bull Soc Fr Derm Syphilol 1903;12:361.

3. Hubler WR Jr, Rudolph AH, Kelleher RM. Milia en plaque. Cutis 1978;22:67-70.

4. Wong SS, Goh CL. Milia en plaque. Clin Exp Dermatol 1999;24:183-185.

5. Terui $H$, Hashimoto $A$

Yamasaki K, Aiba S. Milia en plaque as a distinct follicular hamartoma with cystic trichoepitheliomatous features. Am J Dermatopathol 2016;38:212-217.

6. Wang AR, Bercovitch L. Congenital milia en plaque. Pediatr Dermatol 2016;33:e258-e259.

7. Bridges AG, Lucky AW, Haney G, Mutasim DF. Milia en plaque of the eyelids in childhood: case report and review of the literature.
Pediatr Dermatol 1998;15:282-284.

8. Wollina U. Bilateral milia en plaque of the eyelids: long eyelashes and unibrow-case report and review of literature. Dermatol Surg 2010;36:406-408.

9. Keohane SG, Beveridge GW, Benton EC, Cox NH. Milia en plaque a new site and novel treatment. Clin Exp Dermatol 1996;21:58-60.

10. Calabrese P, Pellicano R, Lomuto $M$, Castelvetere M. Milia en plaque. J Eur Acad Dermatol Venereol 1999:12:195-196.

11. Quist SR, Franke I, Bonnekoh B, Gollnick HP. White papules around the ears: a quiz. Milia en plaque. Acta Derm Venereol 2010;90:445-447.

12. Muñoz-Martínez $R$, Santamarina-Albertos A, Sanz-Muñoz C, Miranda-Romero A. Milia en plaque. Actas Dermosifiliogr 2013;104:638-640.

13. Nambudiri VE, Habib N, Arndt KA, Kane KS. Milia en plaque of the nose: report of a case and successful treatment with topical tretinoin. Pediatrics 2014;133:e1373-1376.

14. Ishiura N, Komine M, Kadono T, et al. A case of milia en plaque successfully treated with oral etretinate. Br J Dermatol 2007;157:1287-1289.

15. Voth $\mathbf{H}$, Reinhard G. Periocular milia en plaque successfully treated by erbium:YAG laser ablation. J Cosmet Laser Ther 2011;13:35-37.

16. Tenna S, Filoni A, Pagliarello C, et al. Eyelid milia en plaque: a treatment challenge with a new $\mathrm{CO}_{2}$ fractional laser. Dermatol Ther 2014;27:65-67.

17. Al-Mutairi N, Joshi A. Bilateral extensive periorbital milia en plaque treated with electrodesiccation. J Cutan Med Surg 2006;10:193-196.

18. Tian G, Liang Y, Wei Z, et al. Successful treatment of milia en plaque on the lip using microwave thermotherapy. I Dermatol 2020;47:e128-e129. 